\title{
Configuring Attention in the Multiscreen Living Room
}

\author{
John Rooksby ${ }^{1 *}$, Timothy E Smith ${ }^{2}$, Alistair Morrison ${ }^{1}$, Mattias Rost ${ }^{1}$, \\ Matthew Chalmers ${ }^{1}$. \\ ${ }^{1}$ University of Glasgow. ${ }^{2}$ University of Edinburgh \\ *john.rooksby@glasgow.ac.uk
}

\begin{abstract}
We have conducted a video study of households in Scotland with cohabiting students and young professionals. In this paper we unpack five examples of how mobile devices are used by people watching television. In the examples we explore how screens are used together a) in a physical ecology, b) in an embodied way, c) in an orderly way, and d) with respect to others. We point out that mobile devices are routinely used to access media that is unconnected and unrelated to media on television, for example for sending and receiving messages, browsing social media, and browsing websites. We suggest that mobile devices are not used to directly enhance television programmes, but to enhance leisure time. We suggest that it is important, when considering mobile devices as second screens, not just to treat these as a design topic, but to pay attention to how they are interactionally integrated into the living room.
\end{abstract}

\section{Introduction}

Screen-based devices are often used in front of the television. Reports by Google (2012), Nielsen (2014) and others have addressed the scale of this phenomenon. Jokela et al (2015), Google (2012) and others have presented generalised patterns of how televisions and other devices are used together. Cruickshank et al (2007), Cesar (2008) and others have identified opportunities for integrating mobile devices with the televisions. However, such studies can obscure the very thing they seek to draw attention to: the mundane everyday phenomenon of using a second screen. In this paper we will explore the local particulars of using second screens. We will look beyond generalised descriptions of how much time is spent 
doing this or that, or what combinations of media are most common. Instead, we will examine in detail the real world, real time ways in which mobile devices are used when watching television.

This paper presents five examples from a video study of four households in Scotland. The examples show cohabiting students and young professionals watching television. Our analysis will draw upon the idea of "multi-screening". Rather than treat this as a matter of direct or technical integration between televisions and mobile devices, we will examine the integration of second screens into the living room in terms of its practical accomplishment on a mundane everyday basis. We see the integration of second screens into the living room as an interactional issue. This paper does not produce design requirements or opportunities, but seeks to characterise and make sense of a domestic setting into which mobile technology and new media are entering.

\section{Television and second screens}

According to a study commissioned by Google (2012), we are living in "the new multi-screen world". They found that people in the USA spend 4.4 hours of their leisure time in front of screens each day, and that two or more screen-based devices are routinely used in sequence or in parallel. They found that $77 \%$ of the times people watch television, they also use a second screen. Clearly, using a device in front of a television is common, but these numbers tell us little about how and why this happens.

\section{Home media}

The term "second screen" is commonly invoked with respect to the use of mobile devices or other smaller screens in conjunction with a primary display. These primary displays are typically larger screens, often a television. Hess et al (2008) characterise the relationship between televisions and second screens in terms of "cross media", and "parallel media". Cross media is the use of a second screen to directly interact with or display information from the primary screen. Parallel media is the use of a second screen in a way that has no technical integration with the primary display, and which may or may not be related to what is on screen.

The academic literature on second screens focuses predominantly on cross media. Cruickshank et al (2007) developed an application for displaying programme information on a mobile device. Cesar et al (2008) describe the design of second screen technology in order to control, enrich, share and transfer television content. Ley et al (2013), and Ogonowski et al (2013) examine how cross media systems are used through equipping and running living laboratories.

Some work does focus on parallel media, particularly the use of social media during television shows. For example Basapur (2012) describes the use of a 
"socially generated information feed", and Schirra et al (2014) discuss how people use Twitter while watching a soap opera. Other work has looked at the use of mobile search while watching television. Some other work on show-relevant app use, for example mobile search, or reading television guides also exists.

Little attention has been paid to what Jokela et al (2015) term "unrelated parallel media". One reason may be that cross media is more readily a design topic: it is reasonable to build and trial a cross media system but less so a parallel media system. Another reason is methodological. There is very little observational work on watching television. It is overwhelmingly studied in a laboratory setting (e.g Geerts et al 2008, McGill et al 2014b), or indirectly through logs (e.g. Schirra et al 2014), surveys (Courtois and D'Heer 2012, McGill et al 2014), probes (Bernhaupt et al 2008) and interviews. These methods have strengths, but they each miss the mundane, everyday, invisible (Tolmie et al 2002) uses of technology. Some video studies of naturally occurring television watching do exist, for example Juhlin and Önnevall (2013) have presented a study of how people gesture when watching sports games in a public bar. They argue that it is important to complement laboratory work with ethnographic fieldwork in ordinary environments. Juhlin and Önnevall chose to study bars because of the relative ease of access to these settings, using these as a proxy for the home.

\section{The home}

Watching television is a common domestic pastime, and a valued social activity for many households (Bernhaupt et al 2008). Of course, the television is not the be all and end all of life in the living room. Watching television can include actively concentrating on what is on-screen, or what Brown \& Barkhuus (2006) refer to as passive viewing: times when the television is on, but other activities take precedence. Geerts et al (2008) point out that people engage with the television and interact with co-present others differently depending on the genre of show. For example people talk more during news, sports and quiz shows than those that require more concentration. Eichner (2014) has pointed out that many popular shows have a predictable format to which viewers can orient to and engage with.

Crabtree et al $(2003,2012)$ O'Brien et al (1999), and Tolmie (2013, Tolmie et al 2002, 2008) draw our attention to the social and physical organisation of home life. They point out that to study work in CSCW need not be to study a job-ofwork, but can encompass practices of home and family life. Shove $(2003,2007)$ pays attention to materiality in the home. Barnham and Harrison (2013) treat collocated couples as a design topic, and Neustaedter et al (2013) refer to family life as a continuous "work in progress". Laurier and Wiggins (2012) have used video to study family meal times. Little attention, particularly video ethnography 

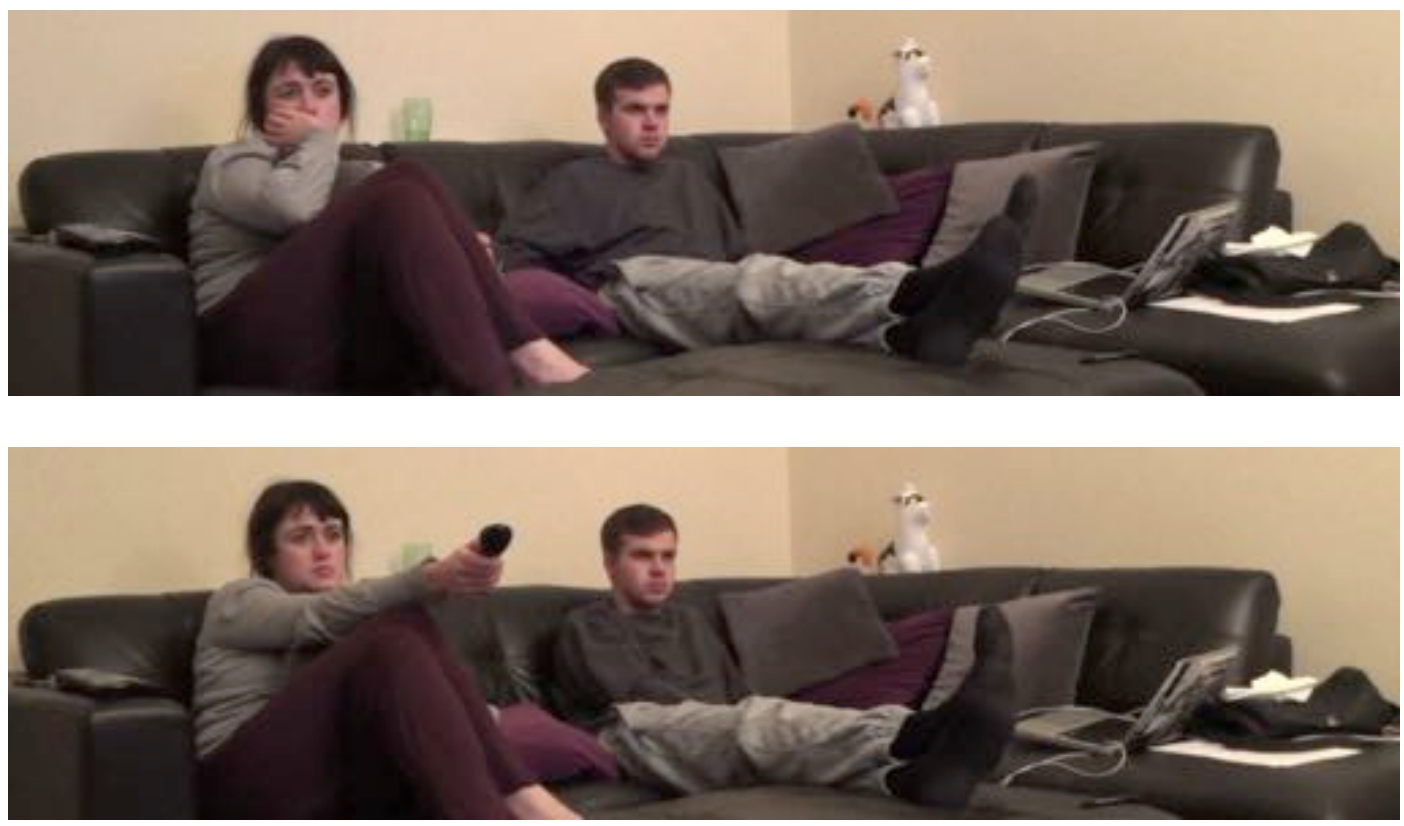

Figure 1: Household one watch Downton Abbey

has paid attention to television viewing, but it is within this CSCW and Sociological literature on domestic life in practice that this paper sits.

\section{A video study of watching television}

In this paper we use examples taken from a video study of people watching television in their own homes. We recruited four households in Scotland for the study. Two households were cohabiting heterosexual couples, one household had two cohabiting heterosexual couples, and a fourth had two female friends. The participants were young professionals or students in their 20 s and early $30 \mathrm{~s}$. We recruited and selected the households using criteria including (a) every member of the household was an adult, (b) every member of the household allowed us to log their mobile phone and consented to being videoed, (c) the household ordinarily watched television in a shared living room. Criterion (a) reflected ethical issues in logging mobile devices, whereas (b) and (c) reflected more pragmatic concerns.

We began the study by installing software on each householders' mobile iOS and Android devices to log the name and time of the apps they used. Additionally we requested that each household videoed themselves when watching television. We visited each household and installed two video cameras, one facing towards the television and one away towards where people were likely to sit. We told the households to turn these cameras on and off as they wished, asking for at least three evenings/periods of video data. We generated over 18 hours of footage in the study. We watched through this footage, taking summary notes and identifying analytical themes. We then went back and transcribed several 

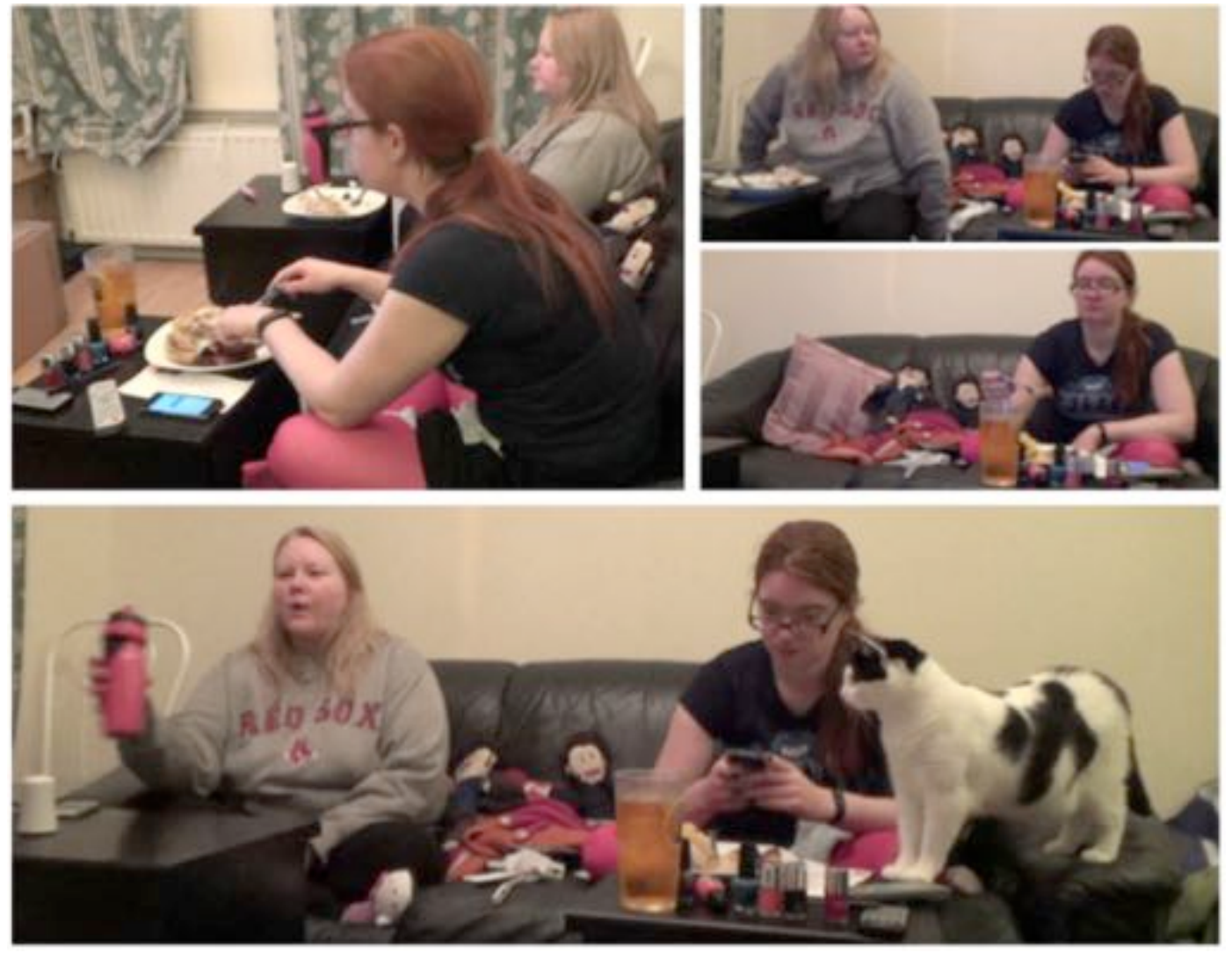

Figure 2: Household two watch The Thick of It

sequences in depth, and organized data sessions to discuss and analyse these. Where the sequences contained conversation, we transcribed this in Jefferson format. However, many of the sequences involved watching in silence or with little talk. Therefore we also created visual transcripts using a graphic transcription format (see Laurier 2014).

\section{Examples}

We will discuss five examples. A graphic transcript is presented for each example (figures 1 to 5). Each transcript represents a sequence of video data. The transcripts are selective, in that particular frames from the two video cameras have been selected. Figures 4 and 5, which both represent relatively long sequences ( 75 seconds and 210 seconds respectively) have been simplified for the paper.

Example 1 (figure 1): Household one watch Downton Abbey

F11 and M11 (household one) are a cohabiting couple. Figure 1 shows them sitting on their sofa watching Downton Abbey (a period drama) using an ondemand service. F11 uses a controller to fast forward through mid-show 

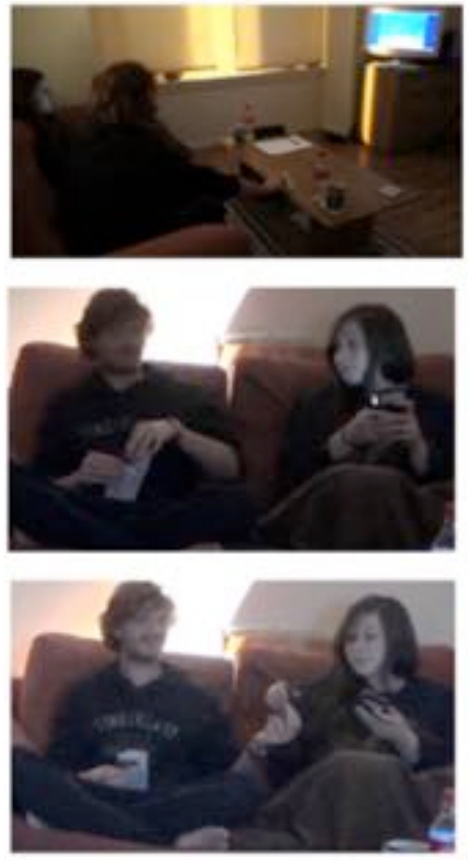
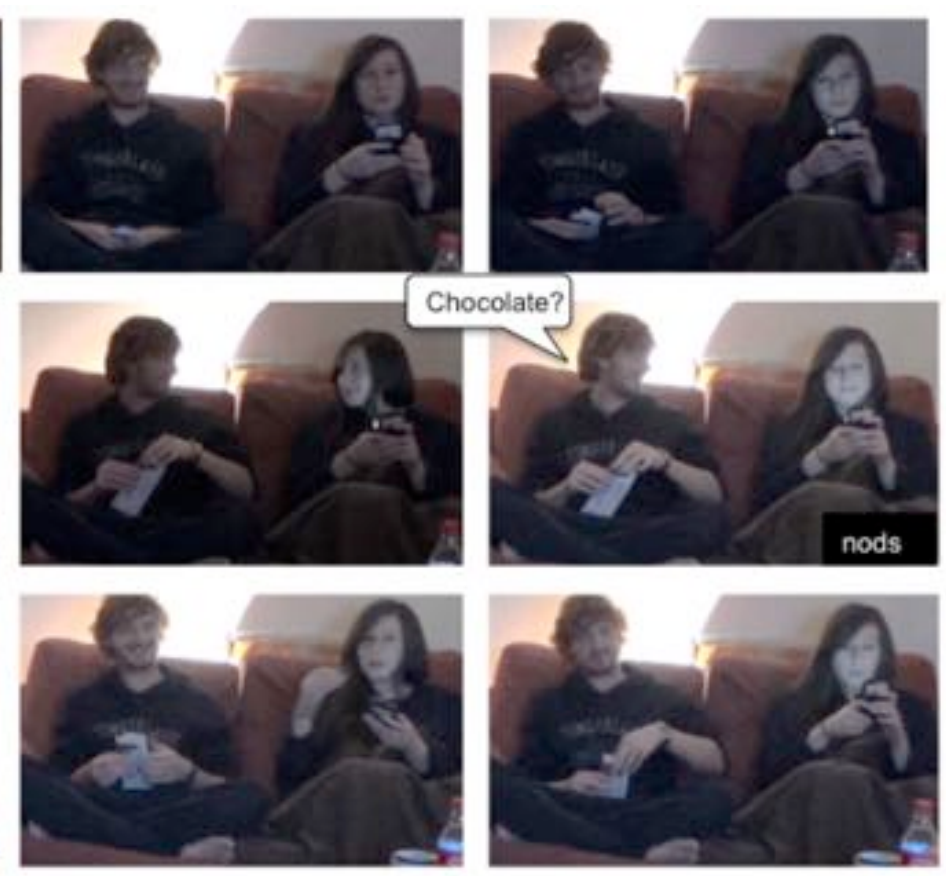

Figure 3: Household three share chocolate while watching Four Lions.

advertisements. They had been holding hands to this point but break hands to pick up the controller. The couple care about Downton Abbey, they have put their digital devices to the side and pay attention.

Example 2 (figure 2): Household 2 watch The Thick of It

F21 and F22 (household two) are housemates. Figure 2 shows them watching The Thick of It (a comedy). They have accessed this show using an on-demand service via a games console. They selected this programme following a short discussion of what they should watch while eating dinner. At the start of figure 2 , they can be seen to be eating their meal. F21 finishes her meal and pushes her table forward. She gets up, looking across to F22's plate. F22 is not eating but has not finished her meal. F22 has received an SMS message, and is typing a reply. F21 leaves the room and comes back without her plate. F22 continues eating.

\section{Example 3 (figure 3): Household 3 watch Four Lions}

M31 and F31 (household 3) are a cohabiting couple. In figure 3 they are watching the comedy film Four Lions. The couple are watching the film shortly after midnight, and are drinking and snacking as they watch. M31 is paying more attention to the film than F31. F31 appears to be following along, but is also using the Facebook app on her phone. M31 takes a bar of chocolate from a plastic bag and begins to open it. F31 looks across to the chocolate and then raises her eyes to M31. M31 notices this and turns to F31. As they make eye contact, F31's expression changes slightly, her eyes widen and she tilts her head forward a little. 

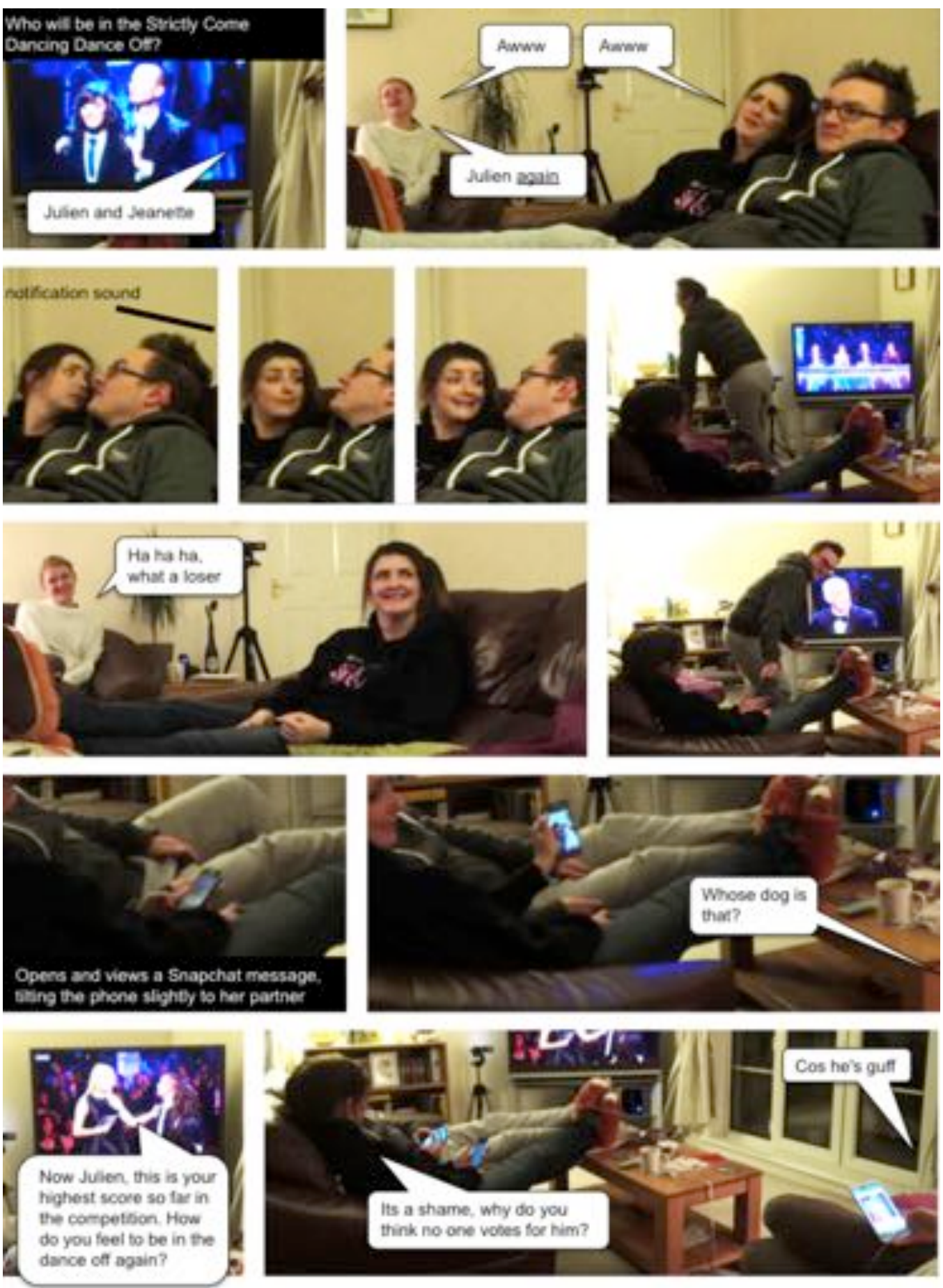

Figure 4: Household four watch Strictly Come Dancing.

M31 asks "chocolate?" F31 moves her gaze back to Facebook and nods and smiles. M31 then gives her a piece of chocolate. F31 browses Facebook while eating the chocolate. 
Example 4 (figure 4): Household 4 watch Strictly Come Dancing

Two couples, F41 and M41, and F42 and M42, live together in household four. In figure 4, F41 and M41 sit together on one sofa, and F42 on another (M42 has gone out to play football). They are watching Strictly Come Dancing, a game show in which celebrities compete in a dancing competition. The example begins at a tense point where the names of the dancers facing possible elimination in a "dance off" are about to be revealed. The females groan together at the announcement "Julien and Janette". At this point F41's phone sounds a notification. Earlier she had left her phone on a surface behind her, and now it is out of reach. She and M41 turn around to look at it, then look at each other. F41 smiles at M41, at first with a closed mouth, and then with raised eyebrows and her teeth showing. M41 gets up to retrieve the phone, something that F42 teases him for, calling him "a loser". M41 hands F41 her phone. She opens Snapchat (a picture messaging app), looks at a picture, then tilts it to M41 who is already looking over her shoulder, and finally she shows it to F42. Then, M41 and F42 both start looking at their own mobile phones; F42 opens Instagram and M41 Facebook. On the television, one of the hosts of Strictly Come Dancing asks Julien how he feels about the lack of votes. F41 comments "It's a shame, why do you think no one votes for him?" to which F42 replies "cos he's guff" (slang, equivalent to "he stinks").

Example 5 (figure 5): Household 4 watch Educating Yorkshire

In household four again, M42 and F42 are seated together, and F41 is sitting separately on another seat (M41 is at work). They are watching but paying little attention to the reality television show Educating Yorkshire. The show concerns life in an English school, with the focus during the example being on how to deal with children smoking. M42 is browsing the real estate app Rightmove. F41 is using her laptop to browse the website of a nightclub called Electric Circus. She announces that the band Pigeon Detectives are coming, and then asks F42 what they sang (evidently remembering the band's name, but not the music). F42 sings some of one of their hit songs, leaning across to M42 as she does so and raising her voice, as if to provoke him. F41 and F42 then realise "that's on camera" and laugh. F42 then offers to play a song on her phone. Despite F41 laughing "Nooo", F42 opens the music app Spotify. While fetching the music she comments about what is happening on TV (a school boy is revealed to be a heavy smoker) "eleven to twenty a day, God!" F41 interjects that she is going away with her boyfriend on Friday. When the advertisements begin, F42 begins playing a Pigeon Detectives song. M42 begins changing channels, settling on another reality television show The Hotel of Mum and Dad. M42 then shouts at F42, saying they do not have to hear the music and that it is loud enough for the whole building to hear. F42 asks M42 why he is "such a grumps". 


\section{Configuring attention}

Following Crabtree et al (2013), we do not attempt to quantify or generalise across occurrences, but will unpack the examples we have presented. Our purpose is to explore the householder's methods: the mundane work of watching television.

\section{The ecology of attention}

In the five examples we can see that the households have each positioned a sofa or sofas facing the television. In example 1 (figure 1) it can clearly be seen that F11 and M11 have set up their living room in such a way that they can spend time reclining and/or eating and drinking together while facing the screen. They have a footstool that doubles up sometimes as a table, and behind them they have a shelf where they place drinks. Objects are placed in and moved between various areas while they view. A glass of water can be seen behind the couple. M11 has his laptop open but to his side on the sofa. He also has placed his bag and some documents with his computer, providing a workspace. He is able to move back and forth between his work on one side and his partner on the other. Both F11 and M11 have mobile phones, which they keep with them and use during the evenings, typically to send and receive messages. F11 has placed hers on the arm of the chair. M11 has his beside him on the sofa, using his computer to charge it. Both of their devices kept on the opposite side to their partner. F11 and M11 have three remote controls in use. Two of these are placed on the arm of the sofa next to F11. The one she is using had been placed on the sofa away from the other two. It may not be ideal to have three controllers, but F11 and M11 seem to keep these organized, knowing which one they need and where this is.

In example 2 (figure 2) the sofa is set opposite the television. The two women each have a table on which to place things. They use this for their meal and a drink, and F22 has also laid out various cosmetic products. This household has at least four remote controls, two of which are placed on F22's table. The controller for the Games Console, which is used to select what to watch, is placed on the sofa between them. Unlike the couples in our study, these two sit well away from each other throughout. Between them sit two dolls. F21 and F22 place their phones on their own table, keeping it screen up and beside their plate as if ready and waiting for a notification. In the first image in the figure, F22's phone has lit just as she receives a message. Neither housemate seems particularly interested in the show, far less so than household one were in Downtown Abbey (and far less so than they are in Dr Who on a subsequent evening). F22 looks down at her phone to write an SMS, ignoring the screen as well as her housemate. F21's silent check of F22's plate is one example of how visual rather than verbal coordination 

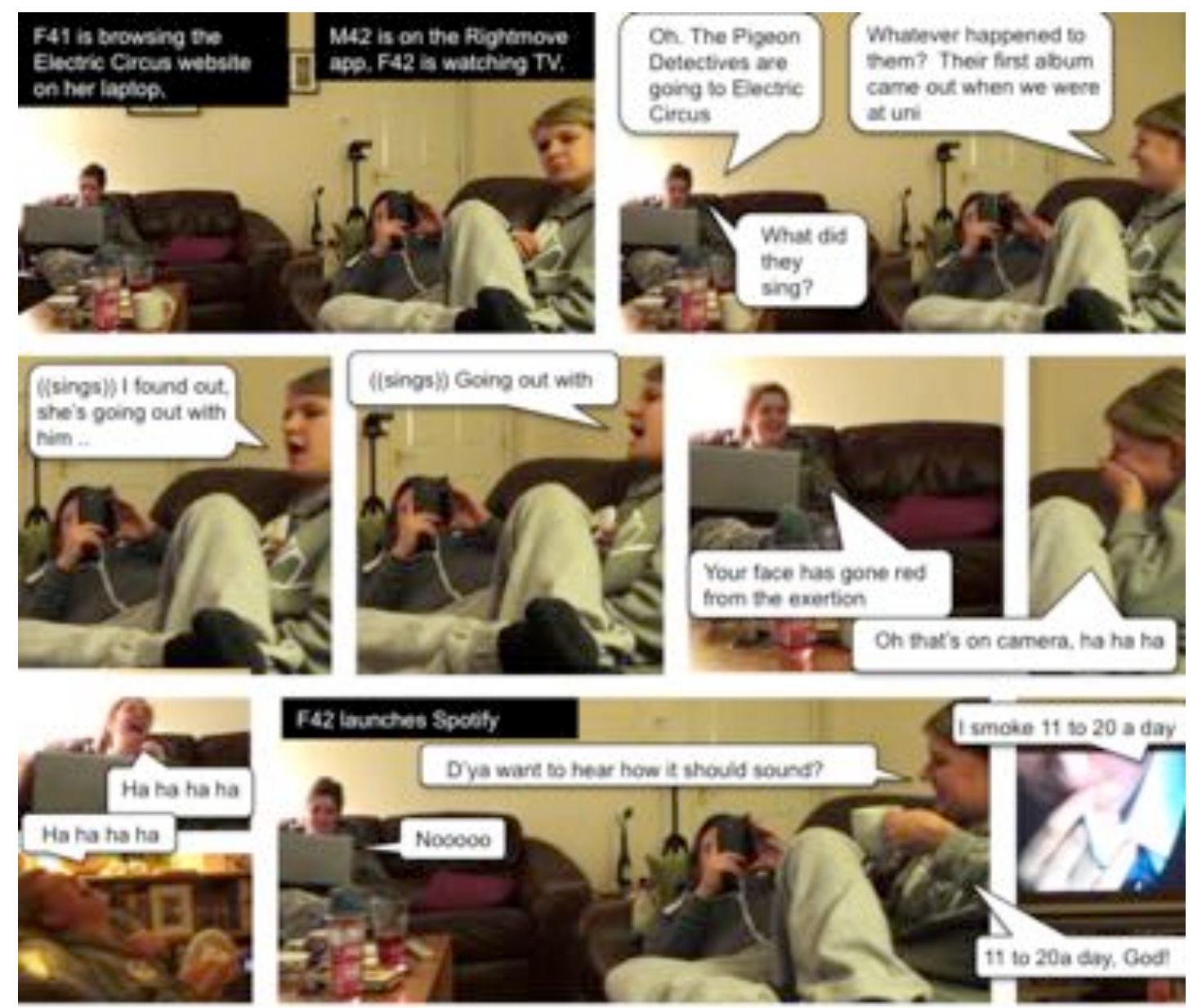
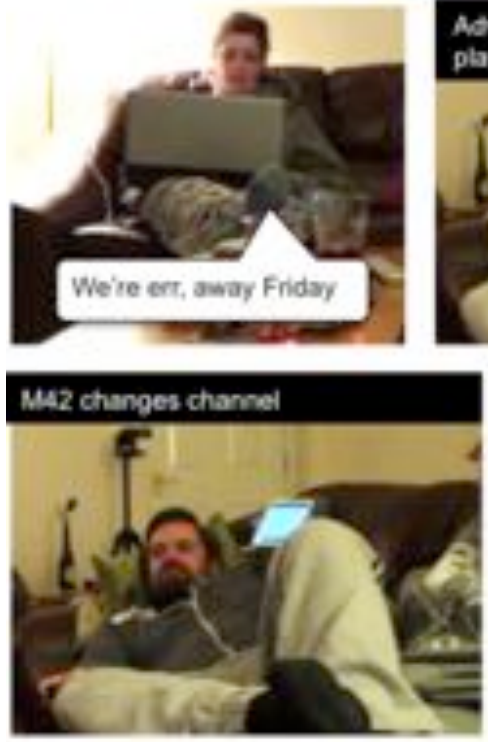
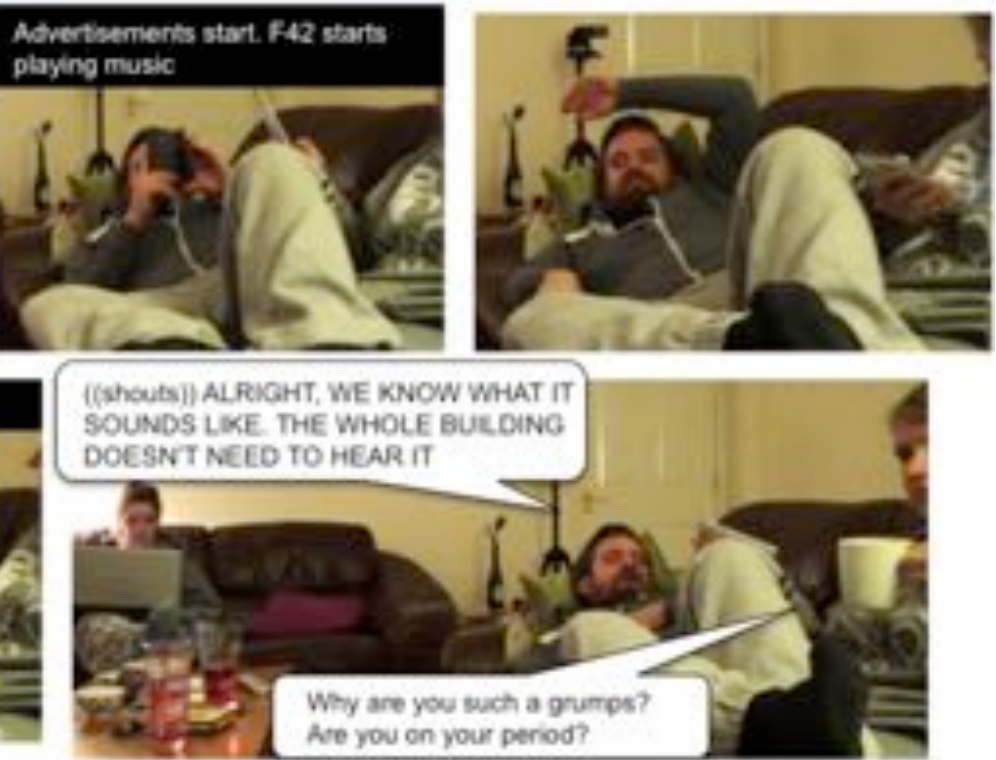

Figure 5: Household four watch Educating Yorkshire

is at play in front of the television. The look orients to the possibility of F21 doing something for F22, but this possibility is not played out at that moment. 
The sofa is, to borrow from Crabtree et al (2003), a centre of activity. It is not just for sitting, but somewhere for watching, eating, drinking, using social media, working, holding hands, painting nails, and so on. These activities draw on and produce an ecological habitat in which various things are situated to facilitate various activities. The living rooms are set up for television watching, with comfortable seating set opposite the television screen. In addition, coffee tables and shelves are used to facilitate activities while watching. The mobile objects used by the participants, including mobile phones and laptops, but also plates of food, glasses of drink, remote controls, documents, cosmetics, and more, easily and unproblematically enter this configured space. These objects are not thrown in randomly but moved around in systematic, routine ways. There are places for food and drink, there are places to put phones and laptops, and so on. Remote controls, of which the households have several, were often placed in a particular configuration with some piled together, and others kept more readily to hand. Mobile phones were often kept to hand (not always, as example four shows). Sometimes these were placed in the pocket, but often they were kept screen-up by the person's side.

\section{Embodied attention}

Watching television is also an embodied activity. Reclining and being comfortable is clearly an important part of watching, to the point where getting up can make someone a "loser" (example 4). The householders would often recline to watch television unless they were eating. We note the householders often adopted particular postures to facilitate watching television and using a device simultaneously. This involved moving the phone to slightly below eye level, making it possible to move between screens with just a shift of the eyes. When someone held their device lower and looked down (e.g. figure 2) this seemed to be to focus specifically on the device. These postures can serve what Brown et al (2013) refer to as a "double duty". They are useful for the person, but also serve as a signal or cue to those around you as to what you are doing. Given that so much television watching goes on in silence, these cues are important.

We also note that couples can and do routinely cuddle or make physical contact with each other while both watching television and using a device. Sitting next to someone using a mobile device also affords looking and showing. In example four, M41 could see the Snapchat image sent to his partner, probably without F41 even needing to tilt her phone. The videos remind us that it is a particular affordance of the mobile phone (as opposed to the plated meal and, to some extent, the book and newspaper) that it can be used when embracing or in close contact with another. 
As Heath et al (2002) have pointed out of workplaces, attention is not just a matter of cognition or mental state but is demonstrably physical, embodied and gone about by the people involved in a methodical manner.

\section{Sequentially ordered attention}

Example 3 (figure 3) shows a couple watching a film. As with the previous examples, the living room is set up to facilitate various activities (including watching, eating and using mobile devices), and various objects (chocolate, drinks and a blanket) are made available for use while they watch. Even though F31 seems to be focusing on Facebook, she is not unaware of her surroundings. She has been laughing from time to time with the film, and she notices when her partner unwraps a chocolate bar. F31's posture is notable, she has adopted a position with her mobile device at chest height that enables her to move her attention back and forth between the screen just by moving her eyes. In the example, F31 solicits an offer of chocolate. She does this by turning to M31, looking at the chocolate in his hand, looking at his face, and smiling. When he asks "chocolate?" she shifts her gaze back to her mobile device (she is viewing Facebook), while nodding her head. F31 has not said anything, but her movements are communicative or accountable. Her shift of attention away from the screens and to her partner functions as a request because it plays to a common sense or routine sequence of action: a snack will be offered for sharing. As such, example 3 portrays not just a sequence of activity, but activity that orients to and invokes a normative sequential order. Eating together does not just happen because chocolate exists, but is made to happen through coordinated, embodied, meaningful interaction.

Example 4 (figure 4) also features a female persuading her partner to do something by looking at him. When she receives a Snapchat message she persuades him to retrieve her phone, which she left earlier on a surface behind her. In this example, all parties orient to the sequence Schegloff (1968) terms the "summons-answer pair": when the phone sounds, pick it up. Notifications can be ignored if necessary (Tolmie et al 2008), but the message arrives as music plays on Strictly Come Dancing, just after the announcement "Julien and Jenette". We suggest that the housemates are orienting here to the format of Strictly Come Dancing. Although F41 and F41 are following the show closely, it is not all consuming of their attention. As Eichner (2014) points out, many shows have a highly structured and predictable format that can be mastered by viewers and serve as a resource for how they watch. The householders know when to engage with Strictly Come Dancing, when to concentrate, when to groan (it is not a coincidence F41 and F41 groan together), when to give assessments and so on. Whereas in example two, F21 and F22 dip in and out of the Thick of It without 
paying much attention, F41 and F42 methodically attend to Strictly Come Dancing. They seem to know when to focus, when they can look away and so on.

After F41 has seen the Snapchat image and showed it to the others in the room, M41 and F42 also start engaging with their devices. It as if F41's Snapchat message leads to viewing social media being taken up as a group activity. But as they do this divergent activity, the females comment on the television show. When the presenter of Strictly Come Dancing invites a contestant to assess his performance, F41 offers her own assessment ("it's a shame") and invites F42 to give one too ("why do you think..."). Pomerantz (1984, p57) points out that assessments are produced as products of participation: they are claims of knowledge about what the speaker is assessing. F41's assessment and call to F42 for another, works to assert their on-going shared attention to the show. F41 is not just saying 'hey look at this', but is making a knowledge claim and calling for a further knowledge claim, with the effect that both women not only attend to the show but call upon and invoke a shared history of attention to this show. Even though F42's assessment "he's guff" is disaffiliative to F41's "it's a shame", the effect is to affirm on-going, convergent attention.

Tolmie et al 2008 and Fischer et al 2013 characterise notifications as interruptions. The notification in this example is out of the flow of on-screen events, but it is matter-of-course for the household. There is nothing disruptive, or unwelcome about it, the only problem is that someone has to stand up to get the phone. Tolmie et al, in their discussion of notifications, call on us to "tackle the issue through a detailed exploration of how interruption handling is accountably managed and organized or ordered, including morally ordered, by cohorts". By paying attention to how a) the housemates organize getting the device and opening the image, and b) the housemates organize ongoing shared attention to the television following the viewing of the image, we can see that they are engaging in behavior that orients to normative order. Their behavior is not controlled by this order, they are not made to answer the phone, are not made to give assessments, but they do this in and as orderly, coordinated viewing.

To call the notification in the example an interruption does seem something of a mischaracterization, in that the term implies that watching television is the important activity. Messages, social media and so on seem very much welcome parts of these householders' evenings. They are part and parcel of their leisure time in the living room. Certainly attention is accountably managed and organized in the course of watching together, but this must be done whether or not alerts are sounding or mobile devices are in use. In looking at mundane household life, we are led to look at what Brown et al (2013) and others refer to as "multi-activity". The literature on multi-activity covers many settings, but is commonly concerned with family life. For example studies of family meal times (Mondada 2009; Laurier and Wiggins, 2011) and family car journeys (Goodwin and Goodwin, 2012) have to deal with how people handle multiple on-going activities. 
Similarly, to watch the television, multiple other events and activities (not just "interruptions") are oriented to and kept in check.

\section{Coordinated attention}

The examples are each of people watching television together with others. It is not the case that watching together involves being quiet so that others can listen. We have seen that watching together is collaboratively achieved (e.g. the assessments of Strictly Come Dancing in example 4). We have also seen that watching together can also involve doing things like eating together (examples 2 and 3). Concerning example 4, we argued that a notification sound is not necessarily interrupting the entertainment but is part of it. Note how when F41 opens the image, she allows M41 to have a look and then shows it to F42. The image arrives to her personal device, but is shared in the group. The reason for sharing is not that it is from someone they all know, but that it is a picture of a dog. As Fischer et al (2013) describe, when a notification arrives to a group setting, the receiver of the message is accountable to the group. F41 did not necessarily have to share the picture, but would have had to explain it somehow.

In example 5 (figure 5), F42 sits with her partner M42, and across from her friend F41. As with the other examples, this example highlights aspects of watching television together with others. However, in this example there is an argument about appropriate behaviour. F41 and F42 are having a jovial conversation about a local nightclub and start discussing a band they remember from their shared past. Meanwhile M42 is engaged with the property app Rightmove on his mobile phone. F41 and F42 have been following the television, while they talk, commenting on it at times. M42 does not communicate with F41 and F42 or comment on the show, but note that he has adopted a posture where he can move his eyes between the television and his phone. This is not the same posture as F31 in example 3, but the effect is the same. M42 does not move or look at F42 when she is singing. Our impression here is not that the mobile phone has cut M42 off from his housemates, but that he is actively using it to cut them off. F42 for her part seems to be trying to provoke attention for M42; when she sings she leans in towards him, looks at him and raises her voice. Trouble does seem to be brewing at this point, and perhaps this is partly why F41 says "nooo" when asked if she wants to hear it, and introduces a new topic "we're away Friday" moments later. Whether or not F41 sees a confrontation brewing, she sees F42's comment "do you want to hear..." and her picking up the phone as indicative of an intention to play music.

It is interesting that F42 waits to the advertisements to play the music, as if it is acceptable for her to sing but not to play music during the programme itself. M42 also seems to orient to this, shouting not at her singing but at her playing music from her phone. Switching channels away from the advertisements and to another 
show may well have to do with underscoring the unacceptability of the music or to avoid the repost but the advertisements are on. While in the previous examples we have shown mobile devices being interwoven with watching, here the device is used in an unacceptable way. Devices are not unproblematic in the living room, but rather that they are (to the main extent) kept unproblematic. When it comes to having to regulate the use of someone's device, it is through a burst of anger. There is no subtle warning, as if F42 should know where the limit to acceptable behaviour is.

A difficulty for us as observers with explaining example 5 is that the confrontation seems embedded in F42 and M42's relationship. It appears that F42 goes out to provoke him. All but one of our examples feature couples watching television. The fact that they are couples is relevant to how they watch. In example 1, M11 and F11 hold hands and watch as a couple. In examples 3 and 4, a female gives her partner not just a look, but a smile. In example 4, M41 does not readily get up to retrieve the phone, but is called upon through F41's looking and smiling at him 'as a boyfriend' to do this favour. The look is intimate, F42's expressions are similar to those described in Kendon's (1990) account of a woman moving in to a kiss. F42 orients to M41 and F41's relationship when she teases M41 for getting up, calling him a "loser". She orients to M41 as being subservient, to him doing her work. As Tolmie (2013) points out, intimacy is witnessable and actionable within mundane action. Tolmie argues that intimacy is a quality of action, rather than an action itself (e.g. not all kisses are intimate, and not all intimate kisses are intimate in the same way). Regarding examples 3 and 4, were they sitting next to a stranger in the cinema or on the bus, they would probably not make requests in the same way, if at all. If such a look was given to a stranger, it would likely be interpreted as a request to be quiet, or met with a "what?" rather than taken as a request to be given something. Our point is, intimacy is recognisable not just from an action but in actions done in particular ways in particular contexts. This does not mean two people sitting together are in a relationship, but means they may have to do work to avoid this assumption. Perhaps this explains the dolls that sit between F21 and F22 in figure 2. With respect to example four, F41 could conceivably have sat next to F42's boyfriend and used puppy eyes to persuade him to pick up her phone, but F42 would probably be upset by this and do something other than tease.

The examples, in various ways, evoke an intimacy of domestic life. This is apparent in the gross sense that the living room is a domestic, private place, but is also apparent in the particulars of watching television. Intimate looks can be given which achieve particular ends. Boyfriends and girlfriends can sit together. Images can get shared first with a partner through virtue of the partner being closest. Television shows can be enjoyed together with a partner and together with a friend in somewhat different ways, and friends have a right to tease couples about their conduct. Whereas examples three and four showed examples 
of couples sharing and doing things for each other, example five is confrontational. However, it is still an intimate scene. The couple are sitting in close contact (a sort of embrace this time), eye contact is made, and cute and teasing language is used "why such a grumps?" What is at issue here is that technology does not feature in the living room as something that brings or breaks intimacy, but rather mobile devices are things that enter an intimate environment and are used with respect to intimacy. Mobile devices do not have fixed roles in this intimate behaviour. A mobile device is present in example four, but as something that is looked away from and then turned back to. Whereas in the previous example three the mobile phone was the object central to a couple's interaction, in this case a bar of chocolate takes that centrality. Intimacy can be played out with relation to a variety of objects, of which the physical mobile phone is just one.

\section{Validity of the study}

We have collected video of people using their own devices in their own homes, at times of their own choosing. We cannot claim our study has captured what would have happened in the households had our cameras not been there. The householders clearly designed some of their activities for the study. For example, in household two, a consideration in the decision to watch The Thick of It was that it was a program during which they didn't mind using their phones. After a while, this household seemed to stop trying to meet our imagined expectations, watching shows they genuinely enjoyed such as Dr Who and putting their devices aside. Other households were similar, for example household one seemed awkward until relaxing into Downton Abbey, during which they put aside their devices. Generally, the cameras seemed to be forgotten as the study progressed, in the sense that the participants stopped designing their actions for the study. Example 5 is a case in point. F41 and F42 remember the camera having sung out loud, which brings embarrassed laughter. But the presence of the camera rapidly becomes irrelevant; the laughter stops and the conversation moves on smoothly (to an argument - something that was unlikely to be "an act" for us). This is typical in video studies, that whether or not people know the camera is there, they end up carrying on (Rooksby 2013; Laurier and Philo, 2006).

Our study has not uniformly captured ordinary life. This suggests it is problematic to do things such as count how often or for how long screens are used together (although possibly no less problematic than diary and other methods for this). Our choice has been to select and unpack individual examples. In doing so, it has been necessary to pay close attention to and reason about how the participants are orienting to the study itself. We have not selected examples that are devoid of an orientation to the study (as example 5 clearly shows), but rather 
we have taken demand characteristics as another observable phenomena that is done by the participants as the watch television.

\section{Implications of the study}

It is not our intention to draw out direct implications or ideas for designing home media. Rather we will speak to how the home is and can be seen and understood when designing and evaluating new technology.

- Multi-screening as practice: When displays are discussed in the computing and design literature, it is often with disembodied terms such as "screen" (e.g. multi-screening, second screens) or "media" (e.g. cross media, parallel media). The effect is to separate them from the physical and social environment in which they are used. The integration of mobile devices with the television is not, and need not be, in terms of there being a technical connection between devices, or there being a logical relationship between the media viewed on different devices. In the examples we do not see people using their mobile phones to control the television, or to discuss shows via social media. We see people actively interweaving unrelated media together. This interweaving is physical, embodied, orderly and coordinated.

- Multi-screening as embedded in leisure time: Mobile devices were not used in front of the television to enhance a television show. Rather, they seem to be in use to bring further things into leisure time, to create more possibilities for entertainment, pleasure and companionship. The idea that messages are "interruptions" or that devices are used to do "sequential" and "parallel" tasks seem mischaracterisations of leisure time. As Harper $(2010,2011)$ points out, when you examine examples of messaging and technology use, there is little evidence that people are as overloaded with floods of information. On the contrary, people seem to be actively bringing more things into their lives. We should not view the mobile device as being brought into television viewing, but the use of mobile devices, the watching of television, and so on as things being brought into leisure.

- Multi-screening as constituent in social and intimate life: It is apparent from our examples that mobile devices have found a place in domestic life. There are claims currently that mobile phones are overused (Lee et al 2014) and distracting and disruptive to relationships Turkle (2011). However, our examples do not chime with this. We see people using devices while together, even when they embrace. These mobile devices do not seem to be fully demanding of attention (unless that is, the user is purposefully ignoring their partner - example five). Using Facebook did not seem to stop F31 noticing her 
partner was eating chocolate. These glances are fleeting, but the embraces we can see are much longer. Perhaps the relative youth of the study participants is of issue here, or perhaps mobile devices are simply becoming less troublesome. As Ling (2009) and O'Hara et al (2014) suggest, over time people make a place for new technologies in their lives.

\section{Conclusion}

In sum, the examples show that paying attention to screens in the living room is not just an issue of cognition, but of the physical, embodied, and orderly management of media in the home. We suggest the design problem is not how to create integrated systems to meet cognitive ability, but to support the practical ways in which people bring media together in the living room. This is not to criticise cross media, but to say all media needs to find its place in the home.

\section{Acknowledgements}

This work was funded by EPSRC award EP/J007617/1 A Population Approach to Ubicomp System Design. We thank the anonymous reviews, Eric Laurier at the University of Edinburgh, and our colleagues in the 'Populations' research programme.

\section{REFERENCES}

Barnham, S. \& Harrison, S. (2013) Designing for collocated couples. In Neustaedter, C., Harrison, S., Sellen, A. (eds.) Connecting families. The impact of new communication technologies on domestic life. Springer: 15-36.

Basapur, S. et al (2012) FANFEEDS: evaluation of socially generated information feed on second screen as a TV show companion. Proc EuroITV 2012: 87-96.

Bernhaupt $\mathrm{R}$ et al (2008) Trends in the living room and beyond: results from ethnographic studies using creative and playful probing. Computers in Entertainment (CIE) 6(1).

Brown, B. \& L. Barkhuus (2006) The television will be revolutionised: Effects of PVRs and filesharing on television watching. Proc ACM CHI'06: 663-666.

Brown, B., McGregor, M., \& Laurier, E. (2013) iPhone in Vivo: Video analysis of mobile device use. Proc ACM CHI'13: 1031-1040.

Cesar, P., Bulterman, D, Jansen AJ (2008) Usages of the Secondary Screen in an Interactive Television Environment: Control, Enrich, Share, and Transfer Television Content. EuroITV 2008.

Courtois C, D'heer (2012) Second Screen Applications and Tablet Users: Constellation, Awareness, Experience, and Interest. EuroITV'12.

Crabtree, A., Rouncefield, M., \& Tolmie, P. (2012) Doing design ethnography. Springer. 
Crabtree, A., Tolmie, P. \& Rouncefield M (2013) How many bloody examples do you want? Fieldwork and generalization. Proc ECSCW'13: 1-20.

Crabtree, A., Rodden, T., Hemmings, T. and Benford, S. (2003) Finding a place for ubicomp in the home, Proc Ubicomp '03: 208-226.

Cruickshank, L., Tsekleves, E., Whitham, R., Hill, A. Kondo, K. (2007). Making Interactive TV Easier to Use: Interface Design For a Second Screen Approach. The Design Journal 10(3)

Eichner, S. (2014) Agency and media reception. Experiencing video games, film and television. Springer.

Fischer, J.E., Reeves, S., Moran, S., Greenhalgh, C., Benford, S. and Rennick-Egglestone, S. (2013).Understanding Mobile Notification Management in Collocated Groups. Proc ECSCW '13.

Geerts, D. Cesar P, Bulterman D (2008) The Implications of Program Genres for the Design of Social Television Systems. ACM uxTV'08.

Goodwin, M.H. \& Goodwin, C. (2012) Car talk: Integrating texts, bodies, and changing landscapes. Semiotica 191-1/4: 257-286.

Google (2012) The New Multiscreen World: Understanding Cross-Platform Consumer Behaviour. Think With Google Newsletter, August 2012.

Harper, R. (ed.) (2011) The connected home: the future of domestic life. London: Springer.

Harper, R. (2010) Texture: Human expression in the age of communication overload. Cambridge: MIT.

Heath, C., Sanchez Svensson M, Hindmarsh J, Luff P, Vom Lehn D. (2002) Configuring awareness. Computer Supported Cooperative Work. vol. 11, no. 3-4, 2002.

Hess, J et al. (2011) Jumping between Devices and Services: Towards an Integrated Concept for Social TV. In Proc EuroITV '11: 11-20.

Jokela, T., Ojala, J., Olsson, T. (2015) A Diary Study on Combining Multiple Information Devices in Everyday Activities and Tasks. Proc CHI'15.

Juhlin, O., \& Önnevall,, E. (2013) On the relation of ordinary gestures to TV screens. General lessons for the design of collaborative interactive techniques. Proc CHI'13: 919-930.

Kendon, A. (1990) Conducting Interaction. Patterns of Behaviour in Focused Encounters. Cambridge University Press.

Laurier, E. (2014) The Graphic Transcript: Poaching Comic Book Grammar for Inscribing the Visual, Spatial and Temporal Aspects of Action. Geography Compass, 8(4), 235-248.

Laurier, E. \& Philo C. (2006) 'Natural problems of naturalistic video data', In: H. Knoblauch, J. Raab, H.-G. Soeffner \& B. Schnettler (Eds.), Video-Analysis Methodology and Methods, Qualitative Audiovisual Data Analysis in Sociology. Oxford: Peter Lang: 183-192.

Laurier, E. \& Wiggins, S. (2011) Finishing the family meal: the interactional organisation of satiety, Appetite 56, 1: 53-64

Lee U, Lee J, Ko M, Lee C, KimY, Yang S, Yatani K, Gweon G, Chung KM, \& Song J. (2014). Hooked on Smartphones: An Exploratory Study of Smartphone Overuse Among College Students. Proc CHI 2014.

Ley, B. et al (2013) Impacts of new technologies on media usage and social behaviour in domestic environments. Behaviour and Information Technology 
Ling, R. \& Donner, J. (2009) Mobile Communication. Polity.

Mondada, L. (2009) The methodical organization of talking and eating: Assessments in dinner conversations. Food and Quality Preference 2009.

McGill, M., Williamson, J., Brewster, S. (2014). How to Lose Friends and Alienate People: Sharing Control of a Single Use TV System. Proc TVX'14, 147-154.

McGill, M., Williamson, J., Brewster, S. (2014b). Mirror, Mirror, on the Wall: Collaborative Screen-Mirroring for Small Groups. Proc. TVX'14: 87-94.

Neustaedter, C., Harrison, S., Sellen, A. (2012). Connecting Families: An Introduction. In Neustaedter, C., Harrison, S., Sellen, A. (eds.) Connecting families. The impact of new communication technologies on domestic life. Springer: 1-14.

Nielsen (2014) Cross Platform Report, Q1 2014. http://www.nielsen.com/ (accessed Feb 2015).

O’Brien, Rodden, T,, Rouncefield, M., \& Hughes, J. (1999) At Home with Technology. An Ethnographic Study of a Set-Top Box Trial. Transactions on Human Computer Interaction (TOCHI), 6(3).

Ogonowski, C. et al. (2013) Designing for the Living Room: Long-Term User Involvement in a Living Lab. Proc CHI'13: 1539-1548.

O’Hara, K., Massimi M,. Harper, R., Rubens, S., \& Morris, J. (2014) Everyday Dwelling with WhatsApp. Proc CSCW'14, 1131-1143.

Pomerantz, A. (1984). Agreeing and disagreeing with assessments: Some features of preferred/dispreferred turn shapes. In J. M. Atkinson \& J. Heritage (Eds.), Structures of Social Action. Cambridge: Cambridge University Press, 57-101.

Rooksby, J. (2013) Does Professional Work Need to be Studied in a Natural Setting? A Secondary Analysis of a Laboratory Study of Software Developers. In Petre M and van der Hoek (eds.) Software Designers in Action. A Human Centric Look at Design Work. Chapman Hall/CRC Press.

Sacks, H. (1992) Lectures on Conversation, Volumes I and II, Edited by G Jefferson, Malden, MA: Blackwell

Schegloff, E, (1969) Sequence in Conversational Openings. American Anthropology 70, 1075-95.

Schirra, S., Huan, S., Bentley, F. (2014) Together Alone: Motivations for Live-Tweeting a Television Series. Proc. CHI'14.

Shove, E. (2003) Comfort Cleanliness and Convenience: The Social Organisation of Normality. Berg.

Shove, E. (2007) The Design of Everyday Life. Berg.

Stokoe, E. (2012) Moving forward with membership categorization analysis: Methods for systematic analysis. Discourse Studies, 14 (3), 277-303

Tolmie, P., Crabtree, A., Rodden, T., \& Benford, S. (2008) Are You Watching This or What? Interruption and the Juggling of Cohorts. Proc ACM CSCW'08.

Tolmie, P. (2013) Everyday Intimacy. Lambert Academic Publishing.

Tolmie, P., Pycock, J., Diggins, T., MacLean, A., \& Karsenty, A. (2002). Unremarkable Computing. Proc CHI'02, 399-406.

Turkle S. (2011) Alone Together. Why We Expect More from Technology and Less from Each Other. Basic Books, 2011. 